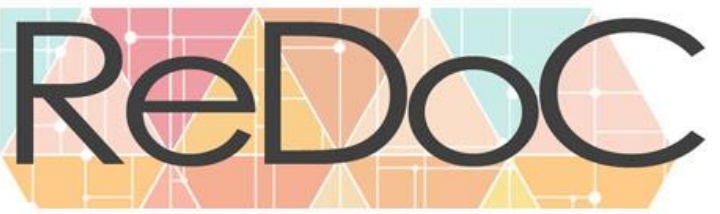

Revista Docência e Cibercultura

\title{
ENSINAR E APRENDER COM AS TECNOLOGIAS DIGITAIS EM REDE: POSSIBILIDADES, DESAFIOS E TENSÕES
}

\section{TEACHING AND LEARNING WITH DIGITAL TECHNOLOGIES IN THE NETWORK: POSSIBILITIES, CHALLENGES AND TENSIONS}

\section{ENSEÑAR Y APRENDER CON LAS TECNOLOGÍAS DIGITALES EN RED: POSIBILIDADES, DESAFÍOS Y TENSIONES}

Julio Lucas de Oliveira ${ }^{1}$

\begin{abstract}
RESUMO: Este artigo é centralizado em discutir as dificuldades do corpo docente na utilização das Tecnologias da Informação e Comunicação (TICs) na prática pedagógica. O objetivo principal da pesquisa é identificar os problemas que causam a falta de preparo, de orientação, de investimento e, até, de interesse por parte dos educadores. A pesquisa traz à tona as questões do despreparo e das barreiras que os professores encontram na utilização das TICs e os receios que os mesmos têm em usá-las, além de buscar explicações para a baixa aplicação de recursos pelo governo, local onde serão realizadas as pesquisas que buscarão responder às questões aqui elencadas e soluções para o desafio de unir tecnologia e educação.
\end{abstract}

Palavras-chaves: prática pedagógica; Tecnologias da Informação e Comunicação; formação continuada.

ABSTRACT: This article is centralized on discussing the difficulties of the teaching staff in the use of Information and Communication Technologies (ICTs) in pedagogical practice. The main goal of the research is to identify the problems that cause the lack of preparation, guidance, investment and even interest on the part of educators. The research brings to the fore the issues of the lack of preparation and of the barriers that teachers encounter in the use of ICTs and the fears that they have to use them, in addition to seeking explanations for the low application of resources by the government, where will be conducted the research will seek to answer the questions listed herein and solutions to the challenge of merging technology and education.

Submetido em: 04/04/2018 - Aceito em: 26/04/2018 - Publicado em: 30/06/2018.

${ }^{1}$ Pedagogia pela Universidade do Estado do Rio de Janeiro (UERJ). 


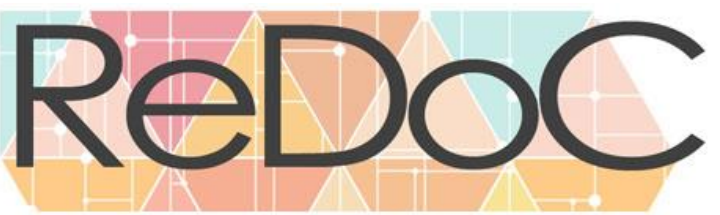

Revista Docência e Cibercultura

Keywords: pedagogical practice; Information and Communication Technologies; training continued.

RESUMÉN: Este artículo se centró en discutir las dificultades del cuerpo docente en la utilización de las Tecnologías de la Información y Comunicación (TIC) en la práctica pedagógica. El objetivo principal de la investigación es identificar los problemas que causan la falta de preparación, de orientación, de inversión y , hasta, de interés por parte de los educadores. La investigación presenta las cuestiones de desesperación y de barreras que los profesores encuentran utilizando las TIC y los recelos que los mismos tienen al usarlas, más allá de buscar explicaciones para la baja aplicación de recursos por el gobierno, lugar donde serán realizadas las investigaciones que buscarán responder a las cuestiones aquí expuestas y soluciones para el desafío de unir tecnología y educación.

Palabras clave: práctica pedagógica; Tecnologías de información y comunicación; entrenamiento continuo

\section{INTRODUÇÃO}

Há mais de três décadas vislumbra-se a oportunidade de utilizar as Tecnologias da Informação e Comunicação (TICs), com primazia, na prática educativa. As TICs são entendidas aqui como uso da informática, do computador, da Internet, CD-ROM, da hipermídia, da multimídia, educação à distância, chats, listas de discussão, correio eletrônico, de celulares e smartphones e de outros recursos e linguagens digitais que podem colaborar para tornar os processos de ensino-aprendizagem mais condizentes com os contextos socioculturais dos estudantes (MORAN; MASSETO; BEHRENS, 2000). Dessa forma, vários programas foram criados nesse período para intermediar a relação educação x tecnologia, baseando-se em experimentos aplicados nos Estados Unidos e Europa. Todavia, os resultados esperados ainda não ocorreram. Uma situação controversa, pois, principalmente nos grandes centros urbanos onde a demanda de tecnologia virtual é maior, há indícios de rejeição à inserção da tecnologia em sala de aula, em especial ao uso de celulares e smartphones.

Atualmente no Brasil, 96\% das unidades escolares estão conectadas à internet e $73 \%$ dos professores já fizeram uso da rede global de computadores, em algum momento, 


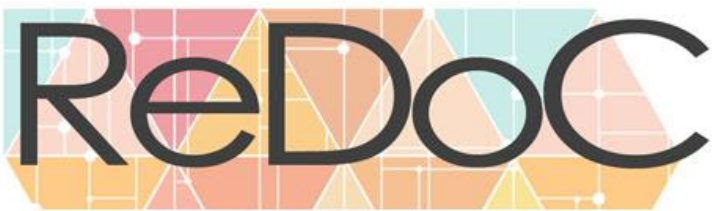

Revista Docência e Cibercultura

na sala de aula, segundo pesquisa "TIC Educação"2. Essa pesquisa é realizada pelo Núcleo de Informação e Coordenação do Ponto BR (NIC.br), ligado ao Comitê Gestor da Internet no Brasil (CGI.br), que tem a atribuição de estabelecer diretrizes estratégicas relacionadas ao uso e desenvolvimento da Internet no Brasil, entre outras atividades correlatas. Na mesma pesquisa, ficou evidenciada a alta conectividade entre estudantes e professores, tanto das redes públicas quanto das particulares. Todavia, as potencialidades pedagógicas continuam aquém do ideal.

Em entrevista à revista eletrônica “O Estado de São Paulo" (2016) ${ }^{3}$, o gerente do Centro Regional de Estudos para o Desenvolvimento da Sociedade da Informação (Cetic.br), ligado ao NIC.br, Alexandre Paiva, alega que os desafios não estão somente na disponibilidade da tecnologia, mas sim na "preparação pedagógica para realizar atividades complexas com tecnologia junto aos alunos."

É inegável que as novas tecnologias da informação estão presentes no cotidiano de muitas pessoas no mundo inteiro. As crianças e adolescentes, cada vez mais, utilizam com destreza as TICs. Entretanto, é notável que esses recursos tecnológicos nem sempre são bem aproveitados, por simples falta de desenvoltura, além de baixos investimentos em políticas públicas, na área de tecnologia na educação, para qualificação dos docentes. Ao citar a falta de desenvoltura, leva-se em consideração o fato de que a grande maioria das pessoas, dentre elas os profissionais da educação, sabem lidar com as redes sociais, internet, mídias sociais, etc, para uso pessoal. Então, onde está a falta de qualificação? Provavelmente, na aplicação, nas possibilidades em utilizá-las de modo a tornar o processo de ensino-aprendizagem mais atraente, contemporâneo e desafiante, não só para o professor, mas também para o discente.

Os cursos de magistério demonstram um déficit no que concerne à formação, em caráter tecnológico, sendo descontextualizado da realidade do professor, não

2 A pesquisa encontra-se disponível em: https://www.cgi.br/publicacao/pesquisa-sobre-o-uso-dastecnologias-de-informacao-e-comunicacao-nas-escolas-brasileiras-tic-educacao-2015/ Acesso em: 20/09/2017.

${ }^{3}$ A entrevista encontra-se disponível em: http://link.estadao.com.br/noticias/cultura-digital,no-brasil-73dos-professores-usam-internet-em-sala-de-aula,10000079005. Acesso em: 28/08/2017. 


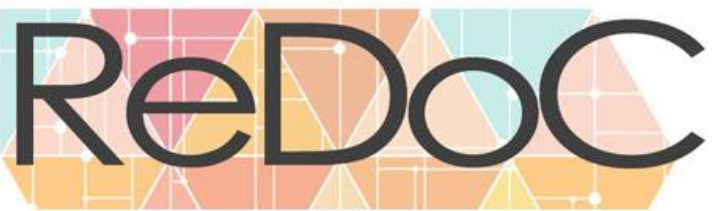

Revista Docência e Cibercultura

considerando a situação efetiva em que ele vive e, assim, não contribuindo para a construção de um ambiente propício para as mudanças educacionais (VALENTE; ALMEIDA, 1997). Portanto, há a necessidade de elucidar as razões pelas quais ainda não se obteve o êxito almejado, de identificar os problemas que causam a falta de preparo, de orientação, de investimento e, até, de interesse por parte dos educadores. Somente com essas respostas será possível transpor-nos a essas dificuldades, permitindo que sejamos capazes de, enquanto docentes, construir metodologias e estratégias de ensino mediadas pelos usos das tecnologias digitais em rede.

Este trabalho, do tipo bibliográfico, adota como referencial teórico, o uso de artigos de periódicos publicados na internet, livros, reportagens e pesquisas recentes sobre o tema. Para isso, alguns de meus interlocutores incluem Edméa Oliveira dos Santos (2002), Dilton Ribeiro do Couto Junior (2009/2013), Helenice Mirabelli Ferreira (2009), José Manuel Moran (2000/2004), Marcos T. Masseto (2000), Maria Aparecida Behrens (2000) e Paulo Freire (1987), Assim, este trabalho acadêmico procurou mostrar e buscar respostas para as causas da baixa utilização dos recursos tecnológicos disponíveis atualmente, passíveis de serem usadas no ambiente escolar.

\section{OS PRINCIPAIS PROGRAMAS}

O Programa Nacional de Tecnologia Educacional (PROINFO), inicialmente denominado Programa Nacional de Informática na Educação, foi criado pelo Ministério da Educação, em parceria com os estados, Distrito Federal e municípios, através da Portaria $\mathrm{n}^{\circ} 522$ de 09 de abril de 1997. A partir de 12 de dezembro de 2007, com a promulgação do Decreto $\mathrm{n}^{\circ} 6.300$ recebeu sua nova nomenclatura. O PROINFO foi criado com o objetivo de promover o uso pedagógico das tecnologias de informação e comunicação nas redes públicas de educação básica (FNDE, 2012), sendo este o principal programa do governo na área de tecnologia da educação e em atividade até hoje. Contudo, o programa prioriza a dotação de infraestrutura de informática, mais precisamente na equipagem de laboratórios, mas não traz, propriamente, em seu escopo a formação 


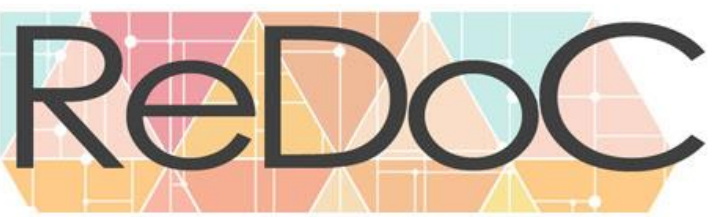

Revista Docência e Cibercultura

continuada plena de educadores para um uso proficiente dos recursos computacionais disponíveis. Assim, o despreparo na execução de tal programa torna-se latente.

Nas palavras de Valente e Almeida (1997), a informática na educação no Brasil iniciou-se na década de 1970, mas só começou a estabelecer-se a partir da década seguinte, ainda no período do governo militar, onde mencionam-se a realização de seminários, comitês, projetos (como o EDUCOM) e programas (a exemplo do PRONINFE). A UNESCO (2009) lançou, a nível internacional, o projeto "Padrões de Competência em TIC para Professores”, com a meta de melhorar a prática docente em todas as áreas de trabalho, buscando qualificar os professores para o uso de novas tecnologias em sala de aula.

Mais recentemente, foi criado pelo governo federal a Política de Inovação de Educação Conectada ${ }^{4}$, cujo objetivo é "apoiar a universalização do acesso à internet em alta velocidade e fomentar o uso pedagógico de tecnologias digitais na educação básica" (MEC/SEB, 2017). Trata-se de mais uma política pública que visa superar as expectativas, onde outros programas não obtiveram êxito. Tem a pretensão de melhorar a velocidade de conexão de internet, qualificar professores para utilizar as novas tecnologias disponíveis, oferecer apoio técnico e financeiro para contratar serviços relacionados, entre outras ações previstas. Somando-se a isso, trata-se de um programa, a exemplo do Proinfo e Banda Larga nas Escolas, que traz propostas parecidas com as antecessoras. Devido ao pouco tempo de implantação ainda não há números que evidenciem avanços ou retrocessos. Se o programa é efetivo, se veio realmente pra produzir transformações, ou se é apenas mais um artifício para mostrar que algo está sendo feito e justificar os altos salários e vantagens que o Ministro da Educação e seus secretários, no uso de suas atribuições, com certeza desfrutam.

O Brasil precisa, sem demora, de diretrizes nacionais que garantam a todos os estados e municípios condições de implementar ações de inovação e uso de tecnologia nas escolas. Porque a tecnologia já se revelou um instrumento eficaz

\footnotetext{
4 A reportagem encontra-se disponível em: https://g1.globo.com/educacao/noticia/governo-lanca-
} programa-para-levar-internet-a-escolas-publicas.ghtml. Acesso em: 01/12/2017. 
para conquistar equidade no acesso ao estudo, contemporaneidade no aprendizado e melhorias na gestão das redes educacionais. (MEC/SEB, 2017).

No decorrer desse período, alguns avanços referentes ao tema foram alcançados, mas não o suficiente para criar uma mentalidade mais pragmática e efetiva na prática educacional. Os projetos de formação continuada para professores, que ainda são poucos, com enfoque em informática educativa também vêm, já há alguns anos, sendo usados como uma contrapartida para a solução do problema, mas ainda não surtiu os efeitos desejados.

\section{OS PROBLEMAS VERIFICADOS}

Sem dúvidas, um dos grandes problemas que se pode apontar é a falta de recursos e de investimento por parte do governo, seja ele municipal, estadual ou federal. São poucos os programas ou projetos verificados que tenham resultados promissores. Mas, além deste, há outros sintomas que demonstram o porquê do despreparo e das dificuldades dos professores na utilização das Tecnologias da Informação e Comunicação (TICs) e os receios que os mesmos têm em usá-las.

\section{BAIXOS INVESTIMEENTOS}

Um estudo recente realizado anualmente pela OCDE (Organização para a Cooperação e Desenvolvimento Econômico) sobre educação, o “Education at a Glance”, revelou nuances da falta de investimento do Governo Federal na educação, especialmente na Educação Básica. Segundo o site da BBC Brasil ${ }^{5}$, o país gasta anualmente US\$ 3,8 mil ( $\mathrm{R} \$ 11,7$ mil) por aluno do primeiro ciclo do ensino fundamental (até a $5^{\mathrm{a}}$ série). O mesmo panorama é visto nos anos finais do Ensino Fundamental e Médio, o que faz com que

\footnotetext{
${ }^{5}$ A reportagem encontra-se disponível em: http://www.bbc.com/portuguese/brasil-41236052. Acesso em: 09/10/2017.
} 


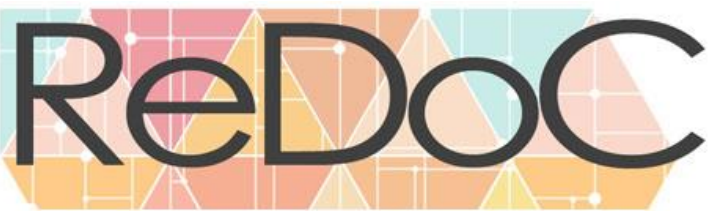

Revista Docência e Cibercultura

amarguemos posições ínfimas. Numa relação de 39 países, o Brasil está entre os últimos. Diferentemente disso, os investimentos no Ensino Superior são três vezes mais do que as despesas no ensino fundamental e médio, se mantendo no mesmo patamar de países europeus.

É como diz um provérbio popular, "descobrir um santo para cobrir outro". Pelo menos é o que representa tal cenário. Essa disparidade na aplicação financeira dificulta $o$ desenvolvimento de ações na Educação Básica, fase onde o desenvolvimento cognitivo está em formação e traz a base que o indivíduo levará para a toda a vida. E o PISA 2015 (Programme for International Student Assessment - Programa Internacional de Avaliação de Estudantes), que avalia estudantes que cursam no mínimo o $7^{\circ}$ ano, demonstra isso. No ranking do programa, também coordenado pela OCDE, o Brasil ficou na $63^{\mathrm{a}}$ posição em ciências, na $59^{\mathrm{a}}$ em leitura e na $66^{\mathrm{a}}$ colocação em matemática, entre 70 países membros e nações convidadas. Ora, se a grande maioria dos estudantes brasileiros tiveram desempenhos que equipara-os a analfabetos funcionais, a grande responsabilidade reside na problemática do baixo investimento em políticas públicas eficazes no anos iniciais da educação e vai tornando-se uma bola de neve com decorrer dos períodos.

No entanto, baixo investimento não é o problema para o ensino superior, que detêm números de países europeus, pelo menos é o que aponta o estudo da OCDE. Nisso, inclui-se a média salarial dos docentes dessa fase do ensino, consideravelmente maior que as outras, além da carga horária menor. Ainda assim, os baixos níveis de acesso ao curso superior que, mesmo mostrando melhoras, ainda está abaixo do ideal, o que vem a reforçar a fragilidade que a pouca aplicação de capital e incentivos, na educação básica, causa quando os jovens atingem graus mais elevados na sua formação escolar.

A partir daí, chegamos a simples conclusão de que há, de fato, pouco investimento no que diz respeito à inserção das TICs no âmbito escolar, uma vez que ele já é baixo na educação como um todo. Desse modo, a formação acadêmica de professores, em infraestrutura e, principalmente, nos jovens fica exacerbadamente prejudicada. 


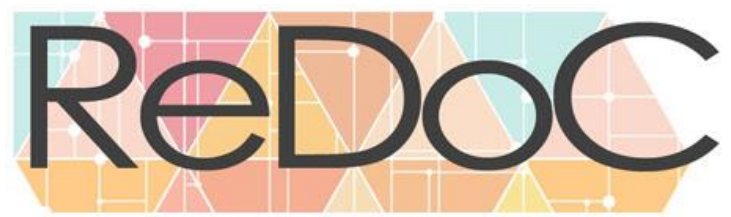

Revista Docência e Cibercultura

\begin{abstract}
Por outro lado, é preciso considerar que o investimento na formação do professor deve ser um processo contínuo e necessário na carreira docente. Para tanto, é preciso que as políticas públicas voltadas para a educação, visem melhores condições para o desempenho das atividades docentes. Devem fomentar incentivar e destinar mais recursos para o processo da formação continuada dos professores da rede pública de ensino. Desse modo, é possível que muitos professores, além de terem acesso a diferentes recursos didáticos, estejam preparados e motivados para experimentá-los nas práticas educativas. (FONSECA; BARRÉRE, 2013, p.4).
\end{abstract}

\title{
A FALTA DE PREPARO
}

Em matéria veiculada pelo Jornal Nacional (2014) ${ }^{6}$, da Rede Globo de Televisão, mostra que parte dos professores rejeitam o uso de computadores em sala de aula, e justamente nas grandes metrópoles onde as tecnologias estão mais presentes. O que torna quantificável a dificuldade que muitos professores ainda têm quando se trata desse tema. Na maioria deles, são docentes já formados há muito tempo e não usufruíram, no período de formação, de qualificação basilar para o uso pedagógico profícuo de computadores. Sendo assim, a formação deve estar à altura de sua atuação. Neste contexto, cabe lembrar aqui as palavras de Moran (2004): "O que deve ter uma sala de aula para uma educação de qualidade? Precisa fundamentalmente de professores bem preparados, motivados e bem remunerados e com formação pedagógica atualizada. Isto é incontestável” (p.3). Somando-se a isso,

\begin{abstract}
A ideia de que o uso de mídias na escola é dificultado pelo pouco manejo que as professoras têm destes meios, especialmente os digitais, vem reforçando que somente as novas gerações seriam capazes de utilizar com destreza os artefatos tecnológicos, colocando em xeque a capacidade docente em criar condições de utilizar câmeras fotográficas, celulares, computadores etc. (COUTO JUNIOR, 2013, p. 141).
\end{abstract}

Vale lembrar ainda que, temos ainda aqueles profissionais que não se predispõe a "bater de frente" com as técnicas convencionais/tradicionais, optando por permanecer nas

\footnotetext{
${ }^{6}$ A reportagem encontra-se disponível em: http://g1.globo.com/jornal-nacional/noticia/2014/09/parte-dosprofessores-acha-computador-desnecessario-no-ensino.html. Acesso em: 29/08/2017.
} 


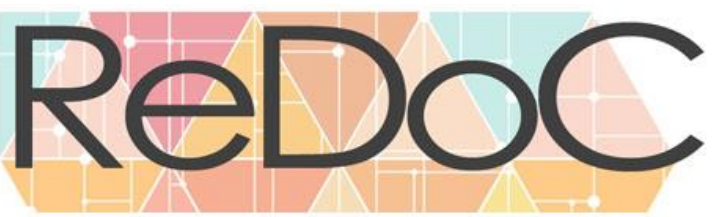

Revista Docência e Cibercultura

antigas práticas educacionais, em detrimento ao que as novidades tecnológicas nos apresentam.

No processo de ensino, a recusa do novo por conta do tradicional ainda é pior. A tecnologia se vista como um elemento estranho será sinônimo de perigo e de ameaças. Muitos profissionais da área de educação que, por pertencerem a uma categoria que, por princípios deveria ter abertura para as novidades, se trancam dentro da "caixa do conformismo", negando ou resistindo as inovações tecnológicas existentes no mundo (SANTOS, J., s/d).

Segundo Moran, Masseto e Behrens (2000), “também há os professores que não aceitam o ensino multimídia, porque parece um modo de ficar brincando de aula...". De acordo com Mercado (s/d), "faltam professores capazes de superar preconceitos e práticas, que rejeitam a tecnologia mantendo uma formação em que predomina a reprodução de modelos substituíveis por outros mais adequados à problemática educacional".

Há de se mencionar a morosidade de parte dos educadores, que não se empenham em atualizar-se, em refinar seu processo de ensino e de proporcionar o aumento da capacidade imaginativa, criativa e intelectual, deles e de seus alunos. Estes encontram-se em um tipo de zona de conforto, preocupados apenas em reproduzir os livros didáticos, realizar atividades mecânicas, avaliações superficiais e previsíveis e, no início do mês, receber seu desvalorizado salário. Ao agir com tamanha detença, eles produzem efeitos contrários a tudo que se espera de profissionais proativos, autênticos e renovadores. Pautados na malfadada “concepção bancária de educação", não praticam a educação com a dialogicidade, a liberdade do pensar, o fomento à criticidade e o saber revolucionário (FREIRE, 1987). Entretanto, cabe frisar que não é tarefa fácil romper com essa concepção de ensino quando muitos professores são formados dentro de uma lógica de mera transmissão de conhecimento.

No fundo, porém, os grandes arquivados são os homens, nesta (na melhor das hipóteses) equivocada concepção 'bancaria da educação. Arquivados, porque, 


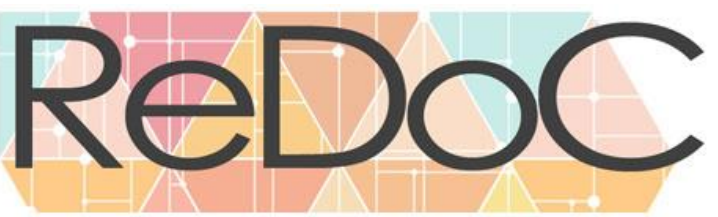

Revista Docência e Cibercultura

fora da busca, fora da práxis, os homens não podem ser. Educador e educandos se arquivam na medida em que, nesta distorcida visão da educação, não há criatividade, não há transformação, não há saber. Só existe saber na invenção, na reinvenção, na busca inquieta, impaciente, permanente, que os homens fazem no mundo, com o mundo e com os outros. (FREIRE, 1987, p. 33)

Em entrevista a Revista VEJA $(2010)^{7}$, o coordenador de comunicação e informação no Brasil da UNESCO, Guilherme Canela Godoi, reconhece a ineficiência em se criar metodologias que permitam empregar os diversos recursos informacionais que poderiam ser benéficos no ambiente educacional. Todavia, o cenário tende a ser pior no Brasil, devidas as grandes limitações que professores brasileiros se deparam, que vão desde o currículo do curso de formação até o acesso restrito à internet e aos laboratórios de informática. Em um determinado trecho de sua entrevista, Godoi coloca que "não se trata de saber ou não usar um computador. Isso é o menor dos problemas. A questão em jogo é como usar equipamentos e recursos tecnológicos em benefício da educação, para fins pedagógicos. Esse é o pulo do gato".

Na verdade, para muitos professores, o uso da informática pode ser danosa para sua metodologia e para a compreensão dos discentes.

"Na navegação muitos alunos se perdem pelas inúmeras possibilidades de navegação e acabam se dispersando. Deve-se orientá-los a selecionar, comparar, sintetizar o que é mais relevante, possibilitando um aprofundamento maior e um conhecimento significativo". (MORAN; MASSETO; BEHRENS, 2000, p. 7).

Novamente, a face do despreparo se escancara, quando os mediadores demonstram-se desatualizados, diante dos recursos tecnológicos. E, para concretizar, citamos o dito "vilão" das salas de aula, os telefones celulares. A alegação é de que torna os alunos dispersos e distantes, não dando a devida atenção que o educador merece. Então, diante de tão forte concorrente e sem o poder de lidar com ele, a alternativa é proibir o

\footnotetext{
${ }^{7}$ A entrevista encontra-se disponível em: http://veja.abril.com.br/educacao/desafio-aos-professores-aliartecnologia-e-educacao-2/. Acesso em: 29/08/2017.
} 


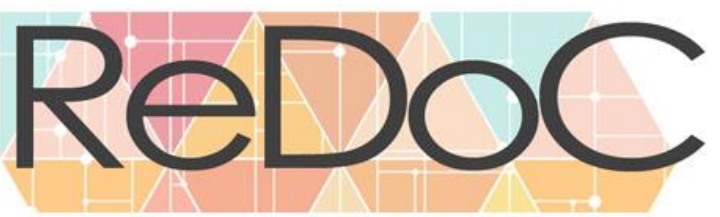

Revista Docência e Cibercultura

uso, perdendo, dessa forma, uma excelente possibilidade de emprego pedagógico do smartphone na construção do conhecimento.

Inclusive, há leis que proíbem o uso de dispositivos móveis em salas de aulas de instituições de ensino público ${ }^{8}$. Todavia, esse cenário, aos poucos, está se alterando. Em algumas cidades já estão sendo promulgadas leis que autorizam a utilização de equipamentos eletrônicos e similares na rede estadual de ensino, caso do estado de São Paulo. "Se quisermos manter o aluno interessado em aprender, temos de usar a linguagem dele. A linguagem de seu tempo"9, disse José Renato Nalini, Secretário de Educação do Estado de São Paulo.

Há a primordialidade em se criar um currículo mais vigoroso e que abranja amplamente os assuntos relacionados à informática na educação. Muitos debates e cursos de formação continuada precisam ser formulados, objetivando a superação do estigma da inimizade entre professor $\mathrm{x}$ tecnologia e criar estratégias para enfrentar outros dilemas alusivos que afligem o professorado.

\section{FALTA DE ACESSO}

Programas como o PROINFO foram criados para dotar de laboratórios de informática as escolas de rede pública de ensino, além de prever cursos de formação continuada aos seus agentes de educação. No entanto, verifica-se que as escolas equipadas com salas destinadas às aulas de informática são pouco frequentadas pelos alunos e pelos professores. Tal fato se dá, simplesmente, para manter as máquinas em bom estado de conservação, pois os órgãos governamentais, que cedem os equipamentos, não se responsabilizam pela sua manutenção, ficando, assim, os reparos devidos a cargo das unidades escolares. Com recursos escassos e verbas voltadas para questões pontuais e de

\footnotetext{
${ }^{8}$ São diversas as leis estaduais que proíbem o uso de celulares em sala de aula. Por exemplo a Lei $\mathrm{n}^{\circ}$ 5.222/08 do Estado do Rio de Janeiro e a Lei no 14.486/02 do Estado de Minas Gerais.

${ }^{9}$ A matéria encontra-se disponível em http://www.educacao.sp.gov.br/noticias/aprovada-lei-que-libera-ouso-do-celular-em-escolas-estaduais-de-sp/. Acesso em: 20/10/2017.
} 


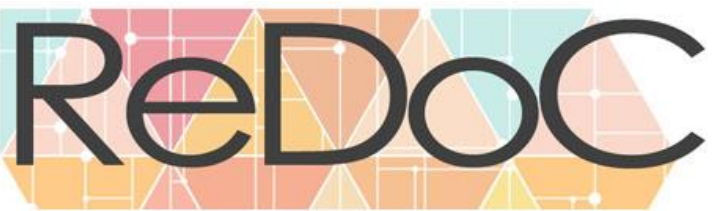

Revista Docência e Cibercultura

primeira necessidade para o funcionamento de escolas, os gestores optam por restringir o acesso aos laboratórios a fim de evitar o desgaste do material.

Outro fato que colabora para a falta de acesso, constitui-se da baixa disponibilidade de sinal WI-FI, principalmente aos alunos. Os altos custos de um plano de internet que atenda plenamente à demanda de unidade de ensino, acessos indevidos e falta de mão-de-obra qualificada para prestar suporte técnico, fiscalizar e criar barreiras para acessos a sites não autorizados e por pessoas alheias às atividades escolares, figuram como as principais causas desta restrição, segundo alguns gestores consultados.

Entrementes, a falta de profissionais habilitados para efetuar reparos, gerir a rede, instalar e atualizar programas, entre outras funções inerentes à TI, é um problema bem antigo. Grande parte das escolas possui laboratórios de informática, equipados com computadores e com acesso à internet, mas, sem alguém especializado que manipule todo o sistema que a constitui, ao primeiro sinal de problema, a solução é interditar a máquina ou deixar de se conectar à web, sem uma presciência de quando será sanado o enguiço.

No entanto, com o advento do Proinfo, foram criados os Núcleos de Tecnologia Educacional (NTE), “estruturas descentralizadas de apoio ao processo de informatização das escolas, auxiliando tanto no processo de incorporação e planejamento da nova tecnologia, quanto no suporte técnico e capacitação dos professores e das equipes administrativas das escolas" (BRASIL/MEC/SEED/ProInfo, 1997, p. 4). Seu propósito é prestar apoio pedagógico e de suporte às instituições escolares e melhorar o acesso à rede, bem como qualificar professores no manuseio e operação dos micros e seus programas. Vinculados às secretarias estaduais ou municipais, os núcleos são implantados conforme a solicitação destes, operando de forma regional, ou seja, atendendo às escolas de determinadas região (BRASIL/MEC/SEED/NTE, p. 2).

Dessa forma, as tentativas de levar educação digital para a sala de aula ficam estritamente comprometida, pois o compartilhamento online de informações não é viável sem o uso de rede. Mesmo com o "Programa Banda Larga nas Escolas"

${ }^{10}$ O programa, instituído em 2008, foi descontinuado. (MEC/SEB, 2017). 


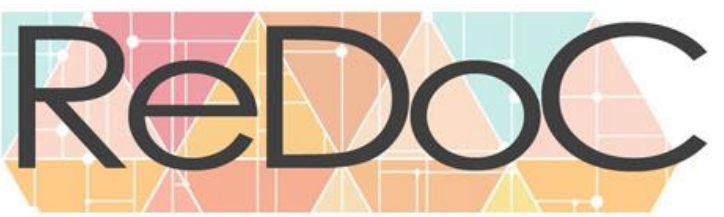

Revista Docência e Cibercultura

conectar todas as escolas públicas à internet com qualidade e velocidade para incrementar o ensino público no país até 2025, essa conexão ficou cerceada à administração das unidades.

\section{A DEVIDA ORIENTAÇÃO}

Os "Padrões de Competência em TICs para Professores", projeto criado pela Organização das Nações Unidas para Educação, Ciência e Cultura (UNESCO), surgiu com o propósito de contribuir para o desenvolvimento profissional dos agentes de educação, parametrizadas em três abordagens fundamentais: alfabetização tecnológica, aprofundamento do conhecimento e criação do conhecimento.

O objetivo geral do projeto não se restringe a melhorar a prática docente, mas
também fazê-lo de forma a contribuir para um sistema de ensino de maior
qualidade que possa, por sua vez, produzir cidadãos mais informados e uma
força de trabalho altamente qualificada, assim impulsionando o
desenvolvimento econômico e social do país. (UNESCO, 2009, p. 4)

No entanto, mesmo com tão bem intencionado projeto, o governo brasileiro não conseguiu ainda, criar uma estrutura apropriada para a aplicação das orientações da publicação, demonstrando um aparente desinteresse no que se refere a esta temática. Antes mesmo da atual crise econômica, os níveis de aplicação de recursos não atendiam plenamente a demanda. Alguns cursos de capacitação, treinamentos e palestras não são o suficiente para trazer uma nova concepção na metodologia educacional vigente. E para que isso seja possível, é preciso criar métodos que ampliem a visão e as técnicas de ensino e rompam com as práticas pedagógicas antigas arraigadas no sistema. E a questão começa na formação.

\footnotetext{
Não se opondo a isso, a formação deve prover condições que para o professor possa construir seu conhecimento sobre as técnicas computacionais, entender por que e como integrar o computador em sua prática pedagógica e ser capaz de superar barreiras de ordem administrativa e pedagógica. Com isso possibilitará a transição de um sistema fragmentado de ensino para uma
} 
abordagem integradora de conteúdos, voltada para a resolução de problemas específicos do interesse de cada educando. (SILVA; SILVA, 2009, p. 3)

O Ministério da Educação traz ainda alguns cursos de capacitação e de formação continuada, que objetivam a promoção do uso das tecnologias digitais de informação na educação. É o caso do Mídias na Educação e do Proinfo Integrado.

Contudo, os programas e cursos sinalizam uma fraqueza concepcional, pois estes não conseguem propagar suas intenções práticas ao público-alvo, no caso os educadores, incidindo na transmissão de conhecimento, nos moldes dos currículos tradicionais e das mídias de massa, mesmo na era da cibercultura (SANTOS, 2002). Estas propostas pecam na falta de visualização da realidade que envolve o cotidiano dos professores. Inclui-se, ainda, o pouco tempo destinado a estas aulas, o que dificultam ou até impedem a disseminação do conteúdo "aprendido" nos cursos.

\section{NECESSIDADE DE MUDANÇA E POSSIBILIDADES METODOLÓGICAS COM O USO DAS TECNOLOGIAS}

Frente às novas concepções pedagógicas que a sociedade necessita para seu desenvolvimento, é mister ressaltar a imprescindibilidade em pensar a educação como um espaço de reflexão, com práticas democráticas e significativas que valorizem os cidadãos envolvidos, propiciando qualidade na educação. E essas novas concepções, tem como "carro-chefe" a necessidade premente de inclusão digital.

\footnotetext{
As perspectivas emancipatórias buscam mudar o foco das políticas e ações, enfatizando a produção de conteúdo digital articulada com as culturas tradicional e digital, superando a dependência das comunidades e estimulandoas à tomada de decisões. Tal abordagem enfatiza a importância da articulação das ações de inclusão digital com as questões educacionais e culturais, e com a promoção da participação política do cidadão, através das TICs. (BONILLA; PRETTO, 2011, p. 37)
}

Para tanto, é preciso abolir a antigas metodologias e primar pela mudança no processo pedagógico. Mas, não é tão somente inserir mídias diversas nas escolas e criar

\begin{tabular}{l|l|l|l|l|l|l|} 
(C) Redoc & Rio de Janeiro & v.2 & n.2 & p. 174 & Maio/Agosto. 2018 & ISSN 2594-9004
\end{tabular}




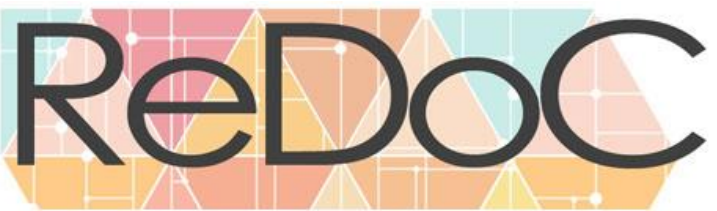

Revista Docência e Cibercultura

cursos que não apresentam a contrapartida aguardada. Mais do que isso, deve-se ouvir e assimilar as carências e dificuldades que o docente enfrenta quando se pensa em informática na educação. Os educadores são, no verdadeiro e amplo sentido da palavra, mediadores do conhecimento e seu preparo é fundamental nesse processo de intermediação entre o antigo e o novo.

\begin{abstract}
As mudanças na educação dependem, em primeiro lugar de termos educadores maduros, intelectuais e emocionalmente curiosos, que saibam motivar e dialogar. O educador autêntico é humilde e confiante, mostra o que sabe, porém está sempre atento ao novo, ensina aprendendo a valorizar a diferença, a improvisar. Aprender por sua vez, é passar da incerteza a uma certeza provisória, pois dará lugar as novas descobertas, não há estagnação no sistema de aprendizagem e descobertas. O novo deve ser questionado, indagado e não aceito sem análise prévia. Por isso é importante termos educadores/ pais, com amadurecimento intelectual, emocional, ético que facilite todo o processo de aprendizagem. As mudanças na educação dependem também de administradores, diretores e coordenadores que atendam todos os níveis do processo educativo. Os alunos também fazem parte da mudança. Alunos curiosos e motivados, ajudam o professor a educar, pois tornam-se interlocutores e parceiros do professor, visando um ambiente culturalmente rico. (MORAN; MASSETO; BEHRENS, 2000, p. 1)
\end{abstract}

Corroborando a visão de Moran, Masseto e Behrens, os alunos também pertencem a essa nova perspectiva. Athayde (2016, p. 13) afirma que "para os estudantes é impossível conceber o mundo sem a existência desses recursos: televisão, vídeo game, celular, computador, internet, redes sociais, e-mails, blogs, os atrativos são tantos, tão fascinantes que fazem a sala de aula tradicional parecer um contexto jurássico". Então, porque não usar toda a desenvoltura tecnológica que lhes têm sido comum? Porque não inverter os papéis e transformar os alunos em mestres e proporcionar efetivamente a troca de saberes? Os finlandeses nos mostram que é possível, viável e salutar para todas as partes envolvidas. Além do exemplo vindo das terras nórdicas, outras alternativas serão apresentadas a seguir.

\title{
ALUNOS-MESTRES
}




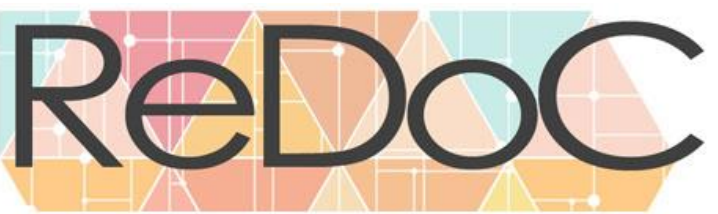

Revista Docência e Cibercultura

A rede de ensino finlandesa, com apoio empresas de tecnologia daquele país, criou um projeto chamado OppilasAgentti ("Agentes Escolares") ${ }^{11}$ que aproveita as competências e habilidades de alunos para dar aulas à seus professores (isso mesmo, aulas) sobre diferentes aparatos tecnológicos e aplicativos, das quais detenham um bom conhecimento. Com isso, desempenham diversas funções assistindo não só aos docentes quanto aos colegas. As escolas também incentiva-os a contribuírem com a comunidade, prestando preleção a idosos e a colegas de outras escolas, suporte técnico nas unidades escolares e ensinado crianças menores a lidar com as novas tecnologias. O custo não deve ser muito oneroso, uma vez que as empresas treinam os jovens nas suas áreas de competência gratuitamente e os "alunos-mestres" são voluntários, não recebendo, assim, quaisquer remuneração. Os únicos prêmios que estes recebem são o reconhecimento de seus talentos, da elevação de sua autoestima, do sentimento de participação ativa dentro da sociedade e serem felizes e orgulhosos fazendo o que gostam, num contex to em que já nasceram mergulhados.

Não é difícil perceber os motivos pelos quais a Finlândia está entre os melhores países nos rankings mundiais de educação. Mesmo que devamos considerar seus altos investimentos em educação, as suas ideias, nada ortodoxas e peculiares, são extremamente inovadoras e, com isso, um sucesso retumbante.

Porém, se estamos sem grandes ideias para por em prática, considero importante nos inspirarmos em projetos como esses que buscam investir nas potencialidades de ensinar-aprender engendrados pelo digital em rede. Criar situações que tendem a estimulá-los, a criarem e recriarem, construírem e reconstruírem, serem colaboradores, reconhecidos e valorizados. Precisamos romper com práticas pedagógicas que, entendidas como recipientes prontos para serem enchidos de conteúdos, sejam capazes de favorecer a promoção de pedagogias dialógicas entre professores e estudantes (FREIRE, 1987).

\footnotetext{
${ }^{11}$ A matéria encontra-se disponível em http://www.bbc.com/portuguese/internacional-42074059. Acesso em: $27 / 11 / 2017$.
} 


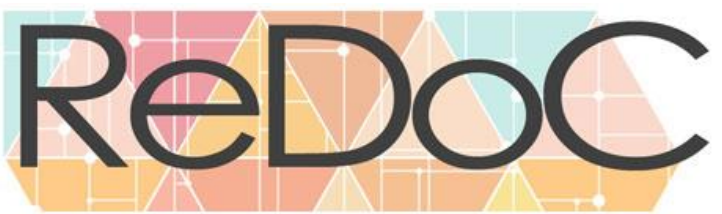

Revista Docência e Cibercultura

\section{EDUCAÇÃO A DISTÂNCIA}

A ideia de Educação a Distância $(\mathrm{EaD})$ já existe há um bom tempo. Sua primeira geração consistia na educação por correspondência, com o conteúdo do curso sendo enviado pelo correio. Na segunda o material impresso ganhou a companhia da TV, fitas de áudio e vídeo, além do telefone convencional. Agora, estamos exatamente na terceira geração, "baseada em redes de conferência por computador e estações de trabalho multimídia, destacando-se as possibilidades oferecidas pelo acesso à internet". (LEMGRUBER, s/d).

A particularidade principal da EaD é a distância geográfica entre professores e estudantes (SANTOS, 2002). Ou seja, estes não dividem os mesmos espaços físicos, como na modalidade presencial. Santos (2002), descreve a docência online como "alvo de inúmeras críticas e preconceitos no tocante à modalidade de educação presencial por não permitir o contato de uma relação face a face". Lemgruber (s/d) também comenta que "alguns consideram que educação à distância, por sua natureza, é sinônimo de educação massificada, de qualidade inferior". Por conseguinte, a metodologia de ensino tradicional, aquela unilateral, onde somente o educador seria o eixo do processo, provoca afastamentos mais concretos do que a longitude pode determinar. Na prática da $\mathrm{EaD}$, por utilizar o ciberespaço, permite-se uma interação mais interpessoal, de todos para todos, transcendendo a perspectiva presencial.

Entretanto, a simples inserção de e-learning não garante reformas na maneira como a educação é conduzida. Conforme citado no artigo de Santos (2002):

\footnotetext{
Reproduz-se o mesmo paradigma do ensino tradicional, em que se tem o professor responsável pela produção e pela transmissão do conhecimento. Mesmo os grupos de discussão, os emails, são ainda, formas de integração muito pobres. Os cursos pela internet acabam considerando que as pessoas são recipientes de informação. A educação continua a ser, mesmo com esses aparatos tecnológicos, o que ela sempre foi: uma obrigação chata, burocrática. Se você não muda o paradigma, as tecnologias acabam servindo para reafirmar o que já se faz. (apud BLIKSTEIN, 2001).
} 


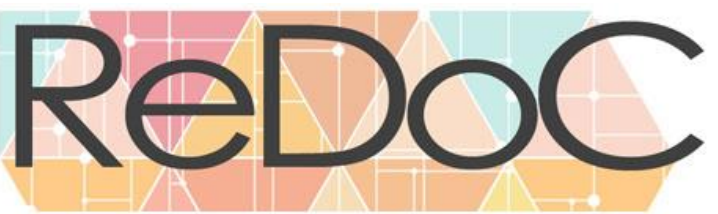

Revista Docência e Cibercultura

Não se trata, unicamente, de assinalar se a forma presencial ou a distância são as mais efetivas ou melhores. Na verdade, a solução para uma prática docente aberta, interativa, auspiciosa e construtiva, é unir os dois modos de comunicação, o presencial e o virtual, e valorizar o melhor de cada um (MORAN; MASSETO; BEHRENS, 2000). Conceber planejamentos que edifiquem o fazer pedagógico, transformando-o numa ação prazerosa e rica em singularidade e inventividade, independente da forma aplicada. E, para isso, os mestres, mediadores do conhecimento, precisam rever suas práxis e servirse de reflexão crítica de seus métodos, para a reconstrução da pedagogia, ainda mais contemporânea.

\section{AS REDES SOCIAIS}

Para Marcon, Machado e Carvalho (2012), "as redes de comunicação digital são a coluna vertebral da sociedade em rede" (apud CASTELLS, 2005). Diante de tal ponto de vista, temos a percepção do quão importante é a capacidade comunicacional da WEB 2.0. A alta interatividade que viabiliza, intensifica a dinâmica da comunicação e confere aos indivíduos uma posição de autores e/ou co-autores nessa interlocução.

\footnotetext{
Sociólogos passaram a pensar a sociedade sob esse viés principalmente a partir do surgimento das tecnologias e das redes sociais digitais, que ganharam evidência com a Web 2.0, fenômeno que caracteriza até então a maior revolução na Internet, uma vez que possibilita a comunicação e o estabelecimento de conexões entre os sujeitos. (MARCON; MACHADO; CARVALHO, 2012, p. 2).
}

Logo, as Redes Sociais são aqui definidas como "uma estrutura social composta por pessoas ou organizações, conectadas por um ou vários tipos de relações, que 


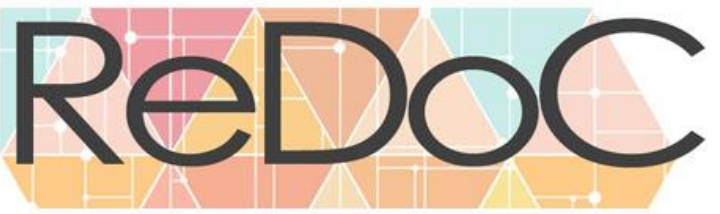

Revista Docência e Cibercultura

compartilham valores e objetivos comuns" ${ }^{\prime 2}$. Nesta conjuntura, também se englobam as unidades de ensino, onde, possivelmente, estão concentradas uma imensa parcela de usuários dessa rede interativa. Isto posto, seu aproveitamento pedagógico é muito abaixo do que seria relevante.

No cotidiano, é notório que as pessoas possuem absoluta sapiência no que tange as redes sociais. Nessas circunstâncias também se incluem agentes educadores e educandos. Fazem uso de todo tipo disponível, a nível pessoal. Apesar disso, essa astúcia para por aí. Os professores mesmo conhecendo essas estruturas, têm dificuldades em desenvolver propostas pedagógicas que se aproveitem da proliferação de mídias digitais em rede. Faltam-lhes, além de formação continuada de qualidade, a bravura de prestar-se a lançar mão de tão interessantes recursos "sócio-tecnológicos". Segundo defende, Couto Junior (2013):

É pertinente questionar que outras experiências sociais [...] vêm sendo
construídas no ciberespaço, e que utilizam suportes responsáveis por criar
ambientes em rede como os blogs, fotoblogs, Orkut, Facebook, Twitter e tantos
outros. Para isso, é necessário que os professores integrem-se a essas redes,
construindo novos olhares atentos aos modos de pensar o ensino e a
aprendizagem dentro das dinâmicas das interfaces digitais
contemporâneas.(p.142).

\section{OS GAMES}

Os jogos de vídeo-game são, há anos, adorados por jovens e por aqueles que vivenciaram o início dessa trajetória, lá pela década de 1980. Desde sua invenção, despertou o interesse dos que viam naquele sistema um meio de criar, de extravasar emoções, de estabelecer relações com outros. E tal fascínio existe até hoje. Por essa e outras razões, os jogos eletrônicos possuem uma grande capacidade em ser um complemento às atividades educacionais.

${ }^{12}$ Retirado do Wikipédia. 


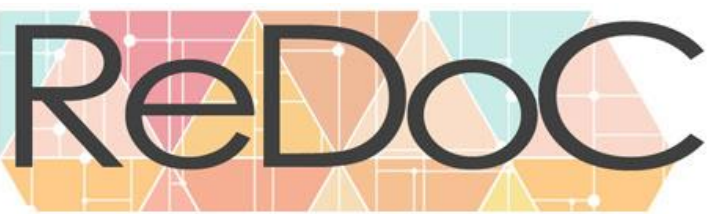

Revista Docência e Cibercultura

Nesse ínterim, os ambientes virtuais onde se desenvolvem os jogos, tem o poder de envolvimento que promove várias habilidades inerentes aos games que, se aproveitado no espaço escolar, podem se configurar como excelente apoio para o crescimento cognitivo dos pubescentes. O "sentimento de imersão", característico desses ambientes (MACHADO, 2002 apud FERREIRA; COUTO JUNIOR, 2009), consegue despertar a senso participativo dos jogadores, além de otimizar o raciocínio lógico, a coordenação motora, noção de espaço, a criatividade e a colaboratividade, que alcançam, sobremaneira, suas rotinas diárias.

À vista disso, esses mesmos pontos são elementos presentes no processo de crescimento cognitivo/intelectual dos jovens nas escolas. Tal comparação deve ser analisada e pensada de forma a introduzi-la nas práticas pedagógicas, fortalecendo o processo educativo e incutindo a atenção e o interesse dos alunos, valendo-se de um equipamento que suscita a interatividade e ludicidade, e que, por ser objeto de desejo da maioria do público juvenil, pertence ao seu mundo. "Nesse sentido, parece muito importante que o campo da educação se debruce sobre essas práticas, buscando subsídios para entender a influência que essa familiarização exerce na escolarização dos jovens". (FERREIRA; COUTO JUNIOR, 2009, p. 4).

\section{SMARTPHONES/CELULARES, OS “VILÕES” DAS SALAS DE AULA}

O quadro-negro, carteiras perfiladas e um professor à frente da sala, "depositando informações na cabeça" dos alunos, como se esses indivíduos fossem invólucros vazios, ainda é uma realidade corrente nas unidades de ensino. É mais do que nítido a rejeição do corpo docente no que refere-se às novas tecnologias. E os celulares são as principais alvos dessa rejeição.

O planejamento para inserção de smartphones em sala de aula precisar ser cuidadosamente refletido, para que da experiência se colha bons frutos. Algumas iniciativas neste campo já começam a florescer e mostrar-nos que, com competência e 


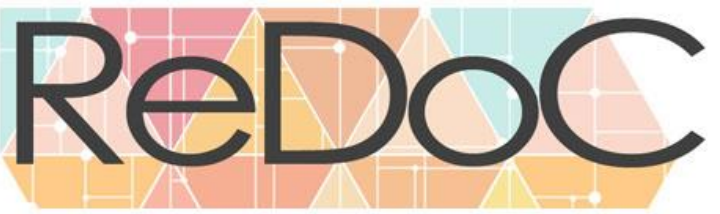

Revista Docência e Cibercultura

inteligência, resultados positivos não são apenas utopia. Em Uberlândia (MG), diversas escolas fazem uso de aparelhos de telefone móvel como recurso pedagógico ${ }^{13}$. A adesão de professores a esta nova tendência de conceber o ensino foi grande e obteve resultados muito satisfatórios na consecução das metas preestabelecidas.

Mais recentemente, em Itatiaia $(\mathrm{RJ})$, similar ideia foi implantada em um colégio da rede municipal de ensino. O programa intitulado "Uso das Tecnologias Digitais" utiliza-se de aplicativos disponíveis para smartphones para ajudar em aulas de matemática. ${ }^{14} \mathrm{O}$ programa aparentou grande aceitação por todos os envolvidos. E a idealização desse projeto partiu diretamente dos professores, que perceberam o quanto este tipo de dispositivo móvel pode ser um aliado na célebre missão de ensinar.

Assim, incentivar processos educacionais através do uso dos telefones celulares, e todas as suas multifunções ao cotidiano das crianças e adolescentes, tende a ser deveras produtivo, pois este equipamento está amplamente difundido na vida desse público, notadamente nos grandes centros urbanos. Entretanto, tal propagação junto aos discentes deve ser feita com parcimônia, de modo a não haver equívocos nem atropelos no que compete a implementação.

\section{CONSIDERAÇÕES FINAIS}

Diante do que fora exposto neste artigo, ficam perceptíveis as dificuldades enfrentadas na implementação da informática no ambiente escolar. Problemas como falta de recursos, de preparo, de investimento, de interesse, qualidade e disponibilização de sinal, entre outras causas, acabam por não permitir uma plena inserção das TICs nas escolas. Apesar de todas as tentativas com programas, projetos, cursos, etc, e também da

\footnotetext{
13 Assunto encontra-se disponível em http://www.correiodeuberlandia.com.br/cidade-e-regiao/celular-eusado-como-recurso-pedagogico/. Acesso em: 28/11/2017.

${ }^{14}$ Mais sobre o assunto em http://odia.ig.com.br/rio-de-janeiro/odiaestado/2017-04-20/professores-usamcelular-para-ensinar-matematica-em-itatiaia.html. Acesso em: 25/11/2017.
} 


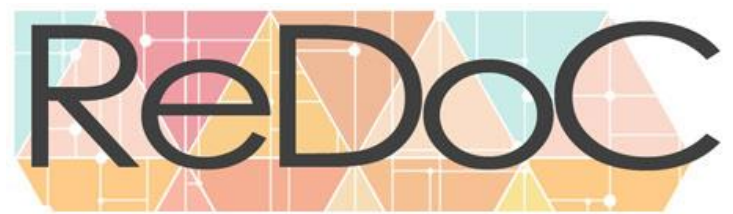

Revista Docência e Cibercultura

difusão que a tecnologia moderna tem no dia-a-dia das pessoas, torna-se necessário tentar compreender os óbices dela em relação à escola.

Fato é que o processo iniciado há mais de duas décadas ainda precisa de muitos ajustes. Principalmente, no que concerne à formação continuada que, para muitos especialistas no assunto, seria o melhor instrumento para se sobrepujar a este obstáculo. Preparar os educadores da nova geração, desde o início de sua formação docente, para que ele possa trabalhar de forma consistente este conhecimento na prática pedagógica. Fazê-lo um profissional mais bem preparado e antenado com as tecnologias digitais em rede que tanto atrai os alunos. Aos professores mais antigos, que viram uma invasão de computadores e smartphones entrarem em seus espaços, sem terem a sabedoria crucial para utilizá-la com perícia, cabe a necessidade de buscarem qualificação e se reinventarem. Serem novos agentes educativos, para auxiliar na promoção de novas propostas de ensino-aprendizagem.

Os novos tempos nos trazem a necessidade da mudança, de repensar a educação por um panorama inovador, tanto nas salas de aulas presenciais, ou laboratórios, quanto nos ambientes virtuais de aprendizagem, complementando-os. Porém, o desafio é grande e os obstáculos são enormes, mas, no entanto, é preciso pontuá-los, buscar remediá-los e trazer ideias coerentes com as situações que a circunstância nos impõe.

\section{REFERÊNCIA}

ATHAYDE, Rafael. Jogos Digitais na Educação Física Escolar: JUST DANCE NOW vai para sala de aula. UFSC. Florianópolis, SC. 2016.

BONILLA, Maria Helena Silveira; PRETTO, Nelson de Luca. Inclusão digital polêmica contemporânea. UFBA. Salvador, BA. EDUFBA. 2013.

CANTINI, Marcos Cesar; BORTOLOZZO, Ana Rita Serenato; FARIA, Daniel da Silva; FABRÍCIO, Fernanda Biazetto Vilar; BASZTABIN, Rogério; MATOS, Elizete. O Desafio do Professor Frente as Novas Tecnologias. S/D.

\begin{tabular}{l|l|l|l|l|l|l|} 
(C) Redoc & Rio de Janeiro & v.2 & n.2 & p. 182 & Maio/Agosto. 2018 & ISSN 2594-9004 \\
\hline
\end{tabular}


CGI.br. Pesquisa sobre o uso das Tecnologias de Informação e Comunicação nas escolas brasileiras - $\quad$ TIC $\quad$ Educação $2015 . \quad$ Disponível em <https://www.cgi.br/publicacao/pesquisa-sobre-o-uso-das-tecnologias-de-informacao-ecomunicacao-nas-escolas-brasileiras-tic-educacao-2015/>. Acesso em 20/SET/2017.

COUTO JUNIOR, Dilton Ribeiro do. Mídias e Educação Infantil: desafios na prática pedagógica. INFORMÁTICA NA EDUCAÇÃO: teoria \& prática, Porto Alegre, RS. 2013.

COUTO JUNIOR, Dilton Ribeiro do; FERREIRA, Helenice Mirabelli Cassino. Jogos Eletrônicos e Educação: Um Diálogo Possível com a Escola. Rio de Janeiro, RJ. 2009.

Fundo Nacional de Desenvolvimento da Educação (FNDE). Sobre o ProInfo. Disponível em <http://www.fnde.gov.br/programas/proinfo/sobre-o-plano-ou-programa/sobre-oproinfo>. Acesso em 18/SET/2017.

FONSECA, Elias Antonio Almeida da; BARRÉRE, Eduardo. Possibilidades e Desafios na Utilização e Seleção de TDIC para o Ensino de Matemática em Escolas Públicas. ULBRA, Canoas, RS. 2013.

FREIRE, Paulo. Pedagogia do Oprimido. $17^{\text {a }}$ Ed. Paz e Terra. Rio de Janeiro, RJ. 1987. GOULART, Nathalia. Desafio aos professores: aliar tecnologia e educação. Disponível em <http://veja.abril.com.br/educacao/desafio-aos-professores-aliar-tecnologia-eeducacao-2/>. VEJA.com. 2010. Acessado em 28/AGO/2017.

Jornal Nacional. Parte dos professores acha o computador desnecessário no ensino. Disponível em <http://g1.globo.com/jornal-nacional/noticia/2014/09/parte-dosprofessores-acha-computador-desnecessario-no-ensino.html $>$ Acessado em 29/AGO/2017.

LEMGRUBER, Márcio Silveira. Educação a Distância: para além dos caixas eletrônicos. UFJF. S/D.

MARCON, Karina; MACHADO, Juliana Brandão; CARVALHO, Marie Jane Soares. Arquiteturas Pedagógicas e Redes Sociais: Uma experiência no Facebook. UFRGS, Rio de Janeiro, RJ. 2012.

MERCADO, Luís Paulo Leopoldo. Formação Docente e Novas Tecnologias. Disponível 


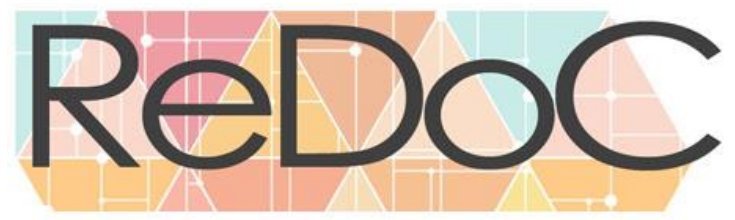

Revista Docência e Cibercultura

<http://www.ufrgs.br/niee/eventos/RIBIE/1998/pdf/com_pos_dem/210M.pdf>. Brasília, DF. 1998. Acessado em 28/AGO/2017.

Ministério da Educação (MEC). Programas do MEC voltados à formação de professores. Disponível em $<$ http://portal.mec.gov.br/component/content/article?id=15944>. Acessado em 01/SET/2017.

Ministério da Educação (MEC)/Secretaria de Educação Básica. Política de Inovação Educação Conectada. Brasília, DF. 2017.

Ministério da Educação (MEC)/Secretaria de Educação a Distância (SEED). Núcleos de Tecnologia Educacional - NTE/Caracterização e Critérios para Criação e Implantação. Brasília, DF. S/D.

MORAN, José Manuel. Os novos espaços de atuação do professor com as tecnologias. São Paulo, PR. 2004.

MORAN, José Manuel; MASETTO, Marcos T.; BEHRENS, Marilda Aparecida. Novas tecnologias e mediação pedagógica. Campinas, SP. Papirus, 2000.

SANTOS, Edméa Oliveira dos. FORMAÇÃo DE PROFESSORES E CIBERCULTURA: novas práticas curriculares na educação presencial e a distância. Salvador, BA. 2002.

SANTOS, José Vicente dos. Formação do Professor Frente às Novas Tecnologias. S/D.

SILVA, Valdirene Maria da; SILVA Sandra Regina Paz da. A Introdução da Informática na Prática Pedagógica dos Professores da Rede Municipal de Ensino de Marechal Deodoro. Marechal Deodoro, AL. 2009-2010.

UNESCO. Padrões de Competência em TIC para Professores - Diretrizes de implementação $\quad$ Versão $\quad \mathbf{1 . 0}$ Disponível em $\langle$ http://unesdoc.unesco.org/images/0015/001562/156209por.pdf $>$. Acessado em 05/SET/2017.

VALENTE, José Armando; ALMEIDA, Fernando José. VISÃO ANALÍTICA DA INFORMÁTICA NA EDUCAÇÃO NO BRASIL: A questão da formação do professor. PUC-SP, São Paulo, SP. 1997. 